\title{
NI VARÓN NI MUJER. REFLEXIONES EN TORNO A LA LEY DE IDENTIDAD DE GÉNERO
}

Neither male nor female. Reflections on the gender identity law

Né maschio né donna. Riflessioni sul diritto sull'identità di genere

\author{
Siro M. A. De Martini ${ }^{1}$
}

Para citar este artículo:

De Martini, S.M.A. (2020). "Ni varón ni mujer. reflexiones en torno a la ley de identidad de género". Prudentia Iuris, N. Aniversario, pp. 323-335. DOI: https://doi.org/10.46553/prudentia.aniversario.2020.pp.323-335

Resumen: La noción de "identidad de género" forma parte de una ideología que niega la verdad básica de la naturaleza humana: el hombre sólo puede ser varón o mujer. Propone, en su lugar, el deseo o el sentimiento como fundamento de la identidad sexual. Con este fundamento, transforma un problema en un derecho y deja desamparados a quienes pretende proteger.

Palabras clave: Género; Identidad de género; Diferencia sexual; Naturaleza humana; Creación.

Abstract: The notion of "gender identity" is part of an ideology that denies a basic human truth: a person can only be male or female. Instead, it places desires or feelings as the basis of sexual identity. With this idea, it transforms a problem to a right and neglects those whom it proposes to protect.

Keywords: Gender; Gender identity; Sexual difference; Human nature; Creation.

1 Doctor en Ciencias Jurídicas, por la Universidad Católica Argentina, Buenos Aires, Argentina. Miembro titular de la Academia Nacional de Derecho y Ciencias Sociales, Argentina. Correo electrónico: sirodemartini@uca.edu.ar. 
Sommario: La nozione di "identità di genere" fa parte di un'ideologia che nega la verità fondamentale della natura umana: l'uomo può essere solo maschio o femmina. Invece, propone il desiderio o il sentimento come fondamento dell'identità sessuale. Con questo fondamento, trasforma un problema in un diritto e lascia impotenti coloro che cerca di proteggere.

Parole chiave: Genere; Identità di genere; Differenza sessuale; Natura umana; Creazione.

\section{1. “Qué buena sesión!”}

Treinta de noviembre del año 2011. Eran las 14 y 48 cuando el presidente de la H. Cámara de Diputados de la Nación, diputado Fellner, dio por abierta la última sesión ordinaria (especial) del año. "Les recuerdo que a las 12 de la noche concluye el período de sesiones ordinarias", enfatizó Fellner ${ }^{2}$. Y en esas horas, les recordó, en esas pocas horas que quedaban por delante, los diputados de la Nación Argentina debían considerar, debatir y eventualmente aprobar los proyectos de ley de "identidad de género", de "muerte digna" y de "fertilización asistida"; entre otras numerosas y variadas iniciativas. Tres proyectos que podrían cambiar la vida, la cultura y el orden profundo de la nación. El tiempo alcanzó para dar media sanción a los dos primeros y una simbólica aprobación "en general" del tercero. Y de este modo, en el transcurso de apenas algo más que una tarde, con el recurrente argumento de la soberanía desorbitada de la voluntad personal, la Cámara de Diputados de la Nación determinó que la naturaleza no existe y que cada uno es lo que siente que es; que, en ciertos casos, hay una suerte de derecho al suicidio asistido; y, a punto estuvo (lo que haría poco tiempo después) de autorizar a cualquier persona mayor de 18 años -sin exigencia ni requisito alguno- a que pueda encomendar a un médico que produzca un ser humano para satisfacer sus deseos.

No es el caso de insistir en la falta de respeto republicana que supone dejar para último momento, y despachar luego sin un serio análisis ni discusión alguna, semejantes proyectos. Pero uno no puede dejar de interrogarse por la razón que pudo haber llevado a tratar a la vez cuestiones como la identidad de género y la "muerte digna". Coincidencia que se repitió en el H. Senado pocos meses más tarde. Quizás la respuesta esté en el entusiasmo impreciso que llevó a la senadora Morandini a exclamar: "Señor presidente: ¡qué buena sesión! [...] En una misma sesión consideramos dos proyectos

2 H. Cámara de Diputados de la Nación. Reunión 10ª - 7ª Sesión Ordinaria (Especial). 
que tienen un sustento común: la voluntad personal para decidir cómo se quiere morir y cómo se quiere vivir"3.

La expresión fue, efectivamente, imprecisa ${ }^{4}$. Sin embargo, la mención de la voluntad personal como fundamento del Derecho e, implícitamente, la concepción de la ley como un instrumento apto para modificar o construir una nueva verdad moral, biológica y, aún, ontológica, es decir, para instalar una ideología, parecen estar en la raíz de algunas de las más importantes leyes sancionadas en nuestro siglo ${ }^{5}$.

Me circunscribiré, según lo anunciado en el título, a reflexionar en torno a una sola de estas leyes: la $\mathrm{N}^{\circ} 26.743$ de identidad de género y, dentro de ella, a la singular cuestión de la definición de esta identidad contenida en la primera parte del artículo $2^{\circ 6}$.

\section{La definición}

En su primer párrafo, el artículo $2^{\circ}$ dice: "Definición. Se entiende por identidad de género a la vivencia interna e individual del género tal como cada persona la siente, la cual puede corresponder o no con el sexo asignado al momento del nacimiento, incluyendo la vivencia personal del cuerpo"7.

Llama la atención el hecho mismo de que el legislador se sienta en la necesidad de definir aquello que constituye la materia de la ley. En efecto, es razonable pensar que las leyes regulan aspectos de la realidad, conductas o situaciones que son conocidas por la sociedad. Más aún cuando se trata de algo tan importante como la identidad de las personas.

3 Cámara de Senadores de la Nación. $5^{\text {a }}$ Reunión $-3^{\text {a }}$ Sesión ordinaria -9 de mayo de 2012.

4 "Imprecisa" porque -salvo supuestos muy acotados- ni la primera permite decidir cómo se quiere morir, ni la segunda, cómo vivir.

5 A las tres mencionadas debe agregarse la Ley $\mathrm{N}^{\circ} 26.618$ y algunos artículos e institutos del CCyC, entre otros.

6 Aunque pudiera parecer innecesario, quizás convenga dejar consignado que las presentes reflexiones toman como punto de análisis la ideología que nutre a la ley. Es decir, de ningún modo implican desconocer el evidente hecho social de la existencia de personas que padecen problemas de identidad sexual, ni los sufrimientos que esto seguramente les produce ni, por supuesto, la injusticia de discriminaciones o malos tratos de que han sido y son objeto.

7 El texto continúa: "Esto puede involucrar la modificación de la apariencia o la función corporal a través de medios farmacológicos, quirúrgicos o de otra índole, siempre que ello sea libremente escogido. También incluye otras expresiones de género, como la vestimenta, el modo de hablar y los modales. Como se puede advertir, se trata de posibilidades que, por tanto, no hacen a la identidad". 
La razón de esta necesidad probablemente radique en que la definición está tomada de los llamados Principios de Yogyakarta ${ }^{8}$ y fue creada por los autores de este documento específicamente para los propósitos de dichos principios $^{9}$. Es decir, básicamente, para crearles una identidad propia a las personas que padecen problemas con su verdadera identidad sexual.

Más allá de que no se trata de un convenio internacional ni estuvieron involucrados en su redacción representantes de países sino algunos expertos en cuestiones de género, LGBT, Derechos Humanos y activistas, la definición trascendió y la repiten numerosos documentos internacionales. No obstante esta amplísima difusión, no he podido encontrar ningún fundamento de ella. Ciertamente, ni en los proyectos que dieron lugar a la Ley $\mathrm{N}^{\circ} 26.743$, ni en el tratamiento parlamentario hay huellas de algún intento de justificarla.

La definición comienza con una apelación al más extremo subjetivismo -y consiguiente relativismo-: cada uno de nosotros es lo que siente que es. Dicho de otro modo, "lo que se siente determina -sin más ni más- lo que se es. Lo que se siente ser es -también- lo que se quiere ser. Por eso, lo que se quiere ser, es"10. En definitiva, el deseo o la imaginación sería el fundamento del ser de las cosas y, en esta materia, de la identidad de las personas.

Volveremos con este tema y sus presupuestos, pero desde ahora se debe puntualizar que esta primera parte de la definición requiere como condición la oración que le sigue, esto es, que lo que se siente "puede corresponder o no con el sexo asignado al momento del nacimiento". En efecto, sólo si la persona no es un ser sexuado, sólo si el sexo no es natural (sino "asignado" y "al momento del nacimiento"), o sólo si no hay naturaleza, puede la voluntad de cada ser humano determinar lo que ese ser humano es.

En la Opinión Consultiva OC-24/1711, la Corte Interamericana de Derechos Humanos hace una distinción terminológica que puede ayudar a comprender el significado de la definición legal. En el punto 32, con citas de distintas fuentes y sin comprometer su propia opinión, distingue: "a) Sexo: En un sentido estricto, el término sexo se refiere a las diferencias biológi-

8 Principios sobre la aplicación de la legislación internacional de Derechos Humanos con relación a la orientación sexual y la identidad de género. Aprobados en dicha ciudad de Indonesia en 2007. Hay un Yogyakarta +10 que agrega unos pocos principios más.

9 En nota dirigida a la comisión encargada de revisar los Principios, Andrew Park, refiere: "[...] the authors created a definition specifically for the purposes of the Yogyakarta Principles”. En Yogyakarta-Review-SOGI-Definition. Pdf.

10 Bianchi, E. T. (19 de noviembre de 2012). "Raíces ideológicas de la identidad de género", $E D$, suplemento, citado por Zannoni, E. A. "Género, Derecho y Justicia”. La Ley 2013-B, 1009 .

11 Ver www.corteidh.or.cr/docs/opiniones/seriea_24_esp. 
cas entre el hombre y la mujer"12, de "b) Sexo asignado al nacer: Esta idea trasciende el concepto de sexo como masculino o femenino y está asociado a la determinación del sexo como una construcción social. La asignación del sexo no es un hecho biológico innato; más bien, el sexo se asigna al nacer con base en la percepción que otros tienen sobre los genitales". La fuente de esta última noción o explicación son los "conceptos básicos" elaborados por la Relatoría de Derechos LGTBI de la Comisión Interamericana de Derechos Humanos. En nota al pie de estos "conceptos básicos" se profundiza la explicación en estos términos: "22 [Sexo asignado al nacer] El sexo anatómico y su presumida dicotomía son el resultado de una lectura ideológica. Por otra parte, asignar el sexo es una decisión social. Podemos utilizar el conocimiento científico para ayudarnos a tomar la decisión, pero solo nuestras creencias sobre el género - no la ciencia- pueden definir nuestro sexo"13.

Más allá de la curiosa paradoja de que sea una explicación enrolada en la ideología de género la que califique de "lectura ideológica" al conocimiento científico (para luego terminar expulsando a la ciencia como fuente de conocimiento valedero), lo cierto es que estos documentos nos permiten comprender el sentido de algunos términos claves de la definición legal. En efecto, en palabras de sus creadores o propagadores, la locución "sexo asignado al nacer" es una construcción social y, como tal, se aparta de la naturaleza, para negar la existencia de dos sexos -masculino y femenino- como un hecho biológico innato. En definitiva, sería una noción que niega la existencia de los sexos tal como los seres humanos la hemos entendido y vivido a lo largo de la historia.

Ahora, ¿es posible negar la existencia de algo tan evidente como la distinción entre varón y mujer? Sabemos que desde el comienzo de nuestra existencia somos ya varones o mujeres, no existe la posibilidad biológica ni antropológica de que no tengamos sexo. Es decir, el ser humano en abstracto, aquel que sería un ser neutro sin determinación sexual alguna, no existe ni puede existir. Esto es un dato de la realidad. La genética ha descubierto hace ya mucho tiempo que toda célula tiene un cromosoma sexual que la hace masculina o femenina ${ }^{14}$. $\mathrm{Y}$ esto ocurre desde que somos un embrión

12 La fuente mediata es: Comité para la Eliminación de la Discriminación contra la Mujer, Recomendación general $\mathrm{N}^{\circ} 28$, relativa al artículo $2^{\circ}$ de la Convención sobre la Eliminación de Todas las Formas de Discriminación contra la Mujer, CEDAW/C/GC/28, 16 de diciembre de 2010 , párr. 5 .

13 Ver http://www.oas.org/es/cidh/multimedia/2015/violencia-lgbti/terminologia-lgbti.html.

14 Mola, L. M.; Rodríguez Gil, S. G.; Rebagliati, P. J. (agosto 2005). "Cromosomas sexuales: Cien años y una historia”. En Encrucijadas, no. 34. Universidad de Buenos Aires. Disponible en http://repositoriouba.sisbi.uba.ar. 
unicelular o cigoto. Es decir que, desde siempre, desde que apareció en el universo ese nuevo, único e irrepetible individuo que somos cada uno de nosotros, somos varones o mujeres y actualmente, todas y cada una de las células de nuestro cuerpo tienen ese mismo cromosoma por el que somos varones o mujeres. No existe otra posibilidad. En palabras de Scola, "el hombre y la mujer son tan persona el uno como la otra, pero sexualmente diferentes. Tal diferencia impregna todo el ser humano hasta la última de sus partículas. En efecto, el cuerpo de hombre es masculino en cada una de sus células, como el de la mujer es femenino"15.

Tendríamos que volver a preguntarnos: ¿es posible negar esto? Ante el hecho de que efectivamente se lo niega y que, incluso, se ha inventado una fórmula para negarlo ("sexo asignado al nacer"), la respuesta tendría que ser: es posible si, y sólo si, reemplazamos el orden natural por una construcción artificial, vale decir, creada por el hombre. Si reemplazamos la creación por la torpe voluntad creacionista del hombre. Una de las más importantes feministas radicales, Shulamith Firestone, lo afirmó a modo de profecía. Escribió en 1970 que concluida la revolución feminista las diferencias genitales entre los seres humanos ya no importarán más culturalmente ${ }^{16}$. Otra feminista, Marina Laski, lo explica diciendo que "la diferencia sexual no es meramente un hecho anatómico, pues la construcción e interpretación de la diferencia anatómica es ella misma un proceso histórico y social. Que el varón y la hembra en la especie difieren es un hecho, pero es un hecho también siempre construido socialmente [...] El sexo y el género no se relacionan entre sí como lo hacen la naturaleza y la cultura pues la sexualidad misma es una diferencia construida culturalmente"17.

\section{La identidad de género como problema}

La ley, como toda norma que trate sobre un aspecto fundamental de la identidad de las personas, tiene como destinatarios a todas las personas. Pero en la realidad, ¿para quiénes fue hecha la ley? Sabemos que los proyectos en los que fundamentalmente se basó fueron obra de la Federación Argentina de Lesbianas, Gays, Bisexuales y Trans (FALGBT) y la Asociación

15 Scola, A. (2003). La cuestión decisiva del amor: hombre-mujer. Madrid. Ed. Encuentro, 16.

16 Firestone, S. (1970). The dialectic of sex. New York. Quill, William Morrow, 19.

17 Laski, M. (1998). "Mujeres, vulnerabilidades y género". Incluido en el Cuaderno Mujer Salud $\mathrm{n}^{\circ}$ 3, de la Red de Salud de las Mujeres Latinoamericanas y del Caribe, 119. 
de Travestis, Transexuales y Transgéneros de Argentina ${ }^{18}$, y la Comunidad Homosexual Argentina (CHA), la Asociación de Lucha por la Identidad Travesti y Transexual (ALITT) y el Movimiento Antidiscriminatorio de Liberación (MAL) ${ }^{19}$. Lo cual es de toda lógica.

Es evidente que la inmensa mayoría de los hombres y las mujeres que habitamos este mundo y, en este caso, Argentina, no tenemos ningún problema con nuestra identidad en materia sexual. Incluyo, por cierto, a los gays, lesbianas y bisexuales cuya característica, en esta materia, no es la identidad sino la orientación sexual.

El tema de la identidad sexual se plantea como problema únicamente para aquellas personas denominadas transexuales o "trans", término del que la Relatoría de Derechos LGBTI de la Comisión Interamericana de Derechos Humanos da la siguiente noción: "Cuando la identidad de género de la persona no corresponde con el sexo asignado al nacer". Tanto la CIDH como la OMS (entre otros) caracterizan a la transexualidad como un "paraguas" o "sombrilla" bajo el cual caben diversas posibilidades.

Es un hecho notable que nuestros legisladores no tuvieran en cuenta que, al momento de sancionarse la Ley $\mathrm{N}^{\circ} 26.743$, el transexualismo estaba incluido en la Clasificación Internacional de Enfermedades (ICD) de la Organización Mundial de la Salud como un desorden mental. Recién en 2018 la OMS, en su ICD-11, lo sacó del capítulo 6 de desórdenes mentales y, con el nuevo nombre de "Incongruencia de género" lo incluyó en el nuevo capítulo 17, llamado "Condiciones relacionadas con la salud sexual" como una disfunción sexual. Esto ha sido considerado como una escala en el camino de la "despatologización" ya que, más allá del cambio de nombre, el transexualismo sigue incluido en este catálogo de enfermedades ${ }^{20}$. La modificación ha sido aprobada por la Asamblea Mundial de la Salud en mayo de 2019 y entrará en vigor en enero de 2022.

Resulta francamente preocupante, entonces, el modo en que nuestra legislación ha encarado la transexualidad, la cual, más allá de que se la considere o no una enfermedad, es, sin dudas, un problema de identidad sexual $^{21}$. Parece increíble que nuestros legisladores, en medio de un clima

18 Expte. 7644-D-2010.

19 Expte. 8126-D-2010.

20 Sobre la evolución histórica del tema: Fernández Rodríguez, M. y ots. “Gender Incongruence is No Longer a Mental Disorder". En www.mentalhealthjournal.org.

21 Ídem. Para la OMS, la incongruencia de género requiere el cumplimiento de al menos dos de los siguientes criterios: "1. Strong dislike or disagreement with primary or secondary sexual characteristics due to incongruence with the experienced gender. 2 . Strong desire to get rid of some of those sexual characteristics due to the incongruence with the experienced gender. 3. Strong desire to have the primary or secondary sexual characteristics of the experienced gender. 4. Strong desire to be treated and accepted as a person of the felt gender". 
de inusual entusiasmo, hayan pensado seriamente que la solución para un problema consista en convertirlo en un derecho. Como si tuviera algún sentido consagrar un derecho a ser trans. Verdad de Perogrullo, una persona transexual tiene todos los mismos derechos fundamentales que tiene cualquier otra persona. Pero no por ser transexual sino por ser persona. La ley argentina, coherente con la errónea idea de que cada cual es lo que siente que es, no exige -para cambiar el nombre o para acceder gratuitamente a una intervención quirúrgica de modificación genital- ni consulta médica, ni tratamiento previo alguno, ni tan siquiera un diagnóstico profesional. Con lo cual deja a la persona absolutamente sola, abandonada a su subjetividad y quizás a su confusión, frente a una decisión que, cuando menos, marcará toda su vida.

\section{Ni varón ni mujer}

Como hemos visto, la locución "sexo asignado al nacer" adoptada por nuestros legisladores implica directamente la negación del sexo como una realidad natural, como un hecho biológico que nos define desde el comienzo de la existencia; y su reemplazo por la idea de construcción social que, en la ley, es entendida como construcción individual. Con lo cual, si bien la ley está claramente destinada a las personas transexuales, su ideologizada definición de identidad de género introduce en nuestro orden jurídico un concepto no sólo erróneo, sino inevitablemente destinado a producir confusión y perplejidad, cuando no a generar problemas en niños y adolescentes en torno a su identidad y naturaleza, por vía de la llamada Educación Sexual Integral.

El hecho es que si cada uno es lo que siente que es y el sexo es una construcción, vale decir algo artificial, creado por el hombre y que, además, es asignado por otros y recién al momento del nacimiento, ninguna persona sería ya varón o mujer en razón de su propio ser, sino que, para serlo, primero tendría que sentirlo. Y seguir sintiéndolo luego. Hasta entonces tendría un sexo provisorio, asignado por la sociedad, sujeto -a través de activistas LGBT e ideólogos de género, devenidos en maestros y profesores- a un permanente bombardeo ideológico tendiente a destruir o, al menos, problematizar la naturaleza humana y, en particular, la propia naturaleza del joven educando.

Vista la definición legal así, y así hay que verla, porque eso es lo que dice, ya no estamos frente a un error legislativo, fruto de la ignorancia o la desidia. Estamos frente a un exitoso intento de trastocar por vía legislativa, educativa y mediática el orden natural de las cosas, mediante la imposición 
de la doctrina revolucionaria del feminismo radical a través de su más logrado instrumento de penetración cultural, esto es, la ideología de género.

\section{La revolución feminista y el fin de las clases sexuales}

Las ideas de que cada cual es -o debe llegar a ser- aquello que siente, desea y quiere, como la de que el sexo es una construcción cultural, no son novedosas y, aunque en los principios de Yogyakarta aparecen en una fórmula de apariencia científica, su origen ideológico puede encontrarse en Engels $^{22}$, luego en Simone de Beauvoir ${ }^{23}$ y, por fin, en Firestone, para no mencionar sino los principales hitos históricos ${ }^{24}$.

Señalaré sólo dos textos de esta última. En el primero expresa que el feminismo no sólo debe cuestionar toda la cultura occidental sino la mismísima "organización de la naturaleza"25. El segundo dice: "[...] así como la meta final de la revolución socialista era no solo acabar con el privilegio de la clase económica, sino con la distinción misma entre clases económicas, la meta definitiva de la revolución feminista debe ser no solo la eliminación del privilegio masculino sino la distinción de sexos misma [...] Una vuelta a un libre pansexualismo probablemente reemplazará la hetero/homo/bisexualidad".

Es decir que: a) la meta final de la revolución feminista es la eliminación de los sexos o clases sexuales ${ }^{26}$; b) el propósito es simétrico al de la revolución marxista, sólo que el feminismo pone el foco en el sexo en lugar de la economía; c) la naturaleza no representa ningún escollo para estos fines, ya que habrá que reinterpretarla o modificarla en el plano ideológico; d) con la desaparición de los sexos sobrevendrá un estado de indistinción y poste-

22 Engels, F. (1964). El origen de la familia, de la propiedad privada y del Estado. Buenos Aires. Ed. Claridad.

23 Beauvoir, Simone de (1949). Le deuxieme sexe. $28^{\text {a }}$ edición. Paris. Gallimard. Su famosa frase, "uno no nace sino que se hace mujer", podría entenderse como una afirmación propia de su existencialismo, filosofía que afirma que la existencia precede a la esencia. Ver Sartre, J. P. (1946). L'existentialisme est un humanisme. Paris. Nagel, 101.

24 He dado un cierto desarrollo al tema en (2018). "Penetración de la ideología de género en el orden jurídico argentino". En Anales de la Academia Nacional de Derecho y Ciencias Sociales. Año LXIII - Segunda Época - Número 56.

25 Ob. cit., 12: "[...] feminist have to question, not just all of Western culture, but the organization of culture itself, and further, even the very organization of nature".

26 No se trata, por cierto, de la desaparición de los órganos genitales sino-como hemos visto- de su reinterpretación cultural como correspondientes a uno u otro sexo. En palabras ahora de Judith Butler, "hombre y masculino podrían significar tanto un cuerpo femenino como uno masculino; mujer y femenino, tanto un cuerpo masculino como uno femenino". En (2007). El género en disputa. Barcelona. Paidós, 54-55. 
rior autodeterminación sexual en el cual cada uno será lo que desee ser, de un modo fluido; e) este estado final -que tiene similares características al comunismo descripto por Marx, en el que cada persona podrá dedicarse de modo cambiante a la actividad que le plazca ${ }^{27}$ - es el pansexualismo. En él, con la desaparición de los sexos, desaparecerán también las hoy llamadas orientaciones sexuales, ya que todas ellas suponen la existencia de la mujer y el varón.

Años después de que Firestone escribiera estas líneas, aparecerá en el mundo la noción de "género" como modo de expresar, precisamente, las alternativas que ofrecerá el pansexualismo, cuando ese nuevo ser, ni varón ni mujer, pueda ser todo -según su deseo e imaginación-, o quizás, con mayor precisión, nada.

\section{La rebelión de la criatura}

La definición de identidad de género contenida en el artículo $2^{\circ}$ de la Ley $\mathrm{N}^{\circ} 26.743$ es, en última instancia, un torpe grito de rebelión contra Dios y su creación. No significa otra cosa que el espectáculo patético del hombre que niega la verdad del hombre: la realidad ontológica, antropológica, psicológica, afectiva y biológica del varón y la mujer tal cual ha sido querida por Dios en su eternidad.

He aquí al hombre, envuelto en la soberbia fantasiosa de que legislar es crear, pretendiendo -a través de las palabras de una definición- hacer desaparecer la verdad de su ser para suplantarla por seres imaginarios, personas cuyo ser sería su querer.

El fenómeno no es, por cierto, nuevo. Este espíritu prometeico, cuya clásica expresión literaria es la obra de Mary Shelley, "Frankenstein o el moderno Prometeo", se remonta al comienzo mismo de la humanidad ${ }^{28}$. Sin embargo, creo que nunca había alcanzado un carácter tan virulento, tan difundido y tan penoso. Se trata de un espíritu que podríamos denominar creacionista, que pretende inventar nuevos seres, desconocer la verdad de otros, desentendiéndose siempre de la realidad. Suplantándola -en las le-

27 Marx, C. y Engels, F., en La ideología alemana, caracterizan de esta forma al comunismo: "En la sociedad comunista, donde cada individuo no tiene acotado un círculo exclusivo de actividades, sino que puede desarrollar sus aptitudes en la rama que mejor le parezca, la sociedad se encarga de regular la producción general, con lo que hace cabalmente posible que yo pueda dedicarme hoy a esto y mañana a aquello, por la mañana cazar, por la tarde pescar y por la noche apacentar el ganado, y después de comer, si me place, dedicarme a criticar, sin necesidad de ser exclusivamente cazador, pescador, pastor o crítico, según los casos [...]" (p. 34).

28 Génesis 3, 5. 
yes, en las palabras- por una realidad ficticia, producto de ideologías o de la voluntad de poder.

En nuestro caso, aprovechando el problema real que algunas personas tienen con su identidad sexual, se ha sancionado una ley que niega la verdad de la naturaleza sexuada del hombre para entronizar en su lugar el deseo como fuente del ser. Como en otros casos, estamos frente a una negación obstinada de la verdad en nombre de una libertad sin límites o, quizás con mayor precisión, de una libertad que atropella y quiere destruir los límites. Es cierto que los límites de la naturaleza humana son, en última instancia, infranqueables. Sin embargo, como toda rebelión de la creatura, deja en su camino las huellas del mal, del desorden, de la confusión.

Benedicto XVI ha caracterizado esta rebelión: "[...] el hombre niega tener una naturaleza preconstituida por su corporeidad, que caracteriza al ser humano. Niega la propia naturaleza y decide que ésta no se le ha dado como hecho preestablecido, sino que es él mismo quien se la debe crear [...] el haber sido creada por Dios como varón y mujer pertenece a la esencia de la criatura humana. Esta dualidad es esencial para el ser humano, tal como Dios la ha dado. Precisamente esta dualidad como dato originario es lo que se impugna [...] No, lo que vale ahora es que no ha sido Él quien los creó varón o mujer, sino que hasta ahora ha sido la sociedad la que lo ha determinado, y ahora somos nosotros mismos quienes hemos de decidir sobre esto. Hombre y mujer como realidad de la creación, como naturaleza de la persona humana, ya no existen. El hombre niega su propia naturaleza [...] En la actualidad, existe sólo el hombre en abstracto, que después elije para sí mismo, autónomamente, una u otra cosa como naturaleza suya. Se niega a hombres y mujeres su exigencia creacional de ser formas de la persona humana que se integran mutuamente"29.

\section{La belleza de la Creación}

No debería terminar esta breve reflexión sobre la patética y peligrosa obra de unos hombres que han actuado como dioses, sin recordar la grandeza incomprensible del hombre -varón y mujer- que Dios creó.

Deberíamos comenzar un canto de alabanza por la obra de Dios. Debemos preguntarnos con el salmista: Señor, "al ver el cielo, obra de tus manos, la luna y las estrellas que has creado: ¿Qué es el hombre para que pienses

29 Discurso a la Curia Romana con motivo de las felicitaciones de Navidad, del 21 de diciembre de 2012 . 
en él, el ser humano para que lo cuides? Lo hiciste poco inferior a los ángeles, lo coronaste de gloria y esplendor"30.

La maravilla del amor de Dios. Su inexplicable misericordia que no sólo nos dio el ser, sino que nos creó a su imagen ${ }^{31}$. Sólo a nosotros, entre todos los seres vivientes.

Juan Pablo II medita que "la vida que Dios da al hombre es original y diversa de la de las demás criaturas vivientes, ya que el hombre, aunque proveniente del polvo de la tierra, es manifestación de Dios en el mundo, signo de su presencia, resplandor de su gloria [...] Al hombre se le ha dado una altísima dignidad, que tiene sus raíces en el vínculo íntimo que lo une a su Creador: en el hombre se refleja la realidad misma de Dios [...] La vida que Dios ofrece al hombre es un don con el que Dios comparte algo de sí mismo con la criatura ${ }^{32}$.

Resplandor de tu gloria, Señor. Estamos misteriosamente unidos a Vos, a Vos que has elegido la vida humana, la vida humana asumida por tu Hijo, como el lugar donde se realiza la salvación para toda la humanidad"33.

En un texto de insondable belleza y misterio, el mismo Santo Padre contempla que "antes de crear al hombre, parece como si el Creador entrara dentro de sí mismo para buscar el modelo y la inspiración en el misterio de su Ser [...] De este misterio surge, por medio de la creación, el ser humano: 'Creó Dios al hombre a imagen suya: a imagen de Dios le creó; varón y mujer los creó" 34 .

He aquí al hombre, manifestación de Dios en el mundo, en su identidad y diferencia ${ }^{35}$. Varón y mujer. Creado a imagen de Dios Uno y Trino.

Varón y mujer, creados por amor y para el amor ${ }^{36}$, cuya fecundidad "es ‘imagen' viva y eficaz, signo visible del acto creador"37.

\section{Bibliografía}

Beauvoir, S. de (1949). Le deuxieme sexe. $28^{a}$ edición. París. Gallimard.

Bianchi, E. T. "Raíces ideológicas de la identidad de género". $E D$, suplemento.

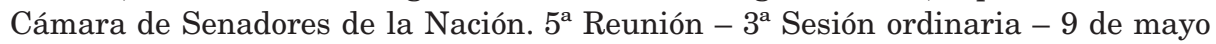
de 2012.

30 Salmo 8, 4/6.

31 Gn. 1, 26.

32 Carta Encíclica Evangelium vitae (EV), n 34.

33 Evangelium vitae, 33.

34 Carta a las familias, $1994, \mathrm{n}^{\circ} 6$.

35 Scola, A. Ob. cit., 18 y sigs.

36 Familiaris consortio, 11.

$37 A L, 10$. 
Carta a las familias, $1994, \mathrm{n}^{\circ} 6$.

Carta Encíclica Evangelium vitae (EV).

Comité para la Eliminación de la Discriminación contra la Mujer, Recomendación general $\mathrm{N}^{\mathrm{o}} 28$ relativa al artículo $2^{\circ}$ de la Convención sobre la Eliminación de Todas las Formas de Discriminación contra la Mujer, CEDAW/C/GC/28, 16 de diciembre de 2010, párr. 5.

corteidh.or.cr/docs/opiniones/seriea_24_esp.

De Martini, S. (2018). "Penetración de la ideología de género en el orden jurídico argentino". En Anales de la Academia Nacional de Derecho y Ciencias Sociales Año LXIII. Segunda Época. Número 56.

Diario del 19 de noviembre de 2012, citado por Zannoni, E. A. "Género, Derecho y Justicia”. La Ley 2013-B, 1009.

Discurso a la Curia Romana con motivo de las felicitaciones de Navidad, del 21 de diciembre de 2012.

Engels, F. (1964). El origen de la Familia, de la propiedad privada y del Estado. Buenos Aires. Ed. Claridad.

Fernández Rodríguez, M. y ots. "Gender Incongruence is No Longer a Mental Disorder”. En www.mentalhealthjournal.org.

Firestone, S, (1970). The dialectic of sex. New York. Quill, William Morrow.

Génesis 1, 26.

Génesis 3, 5.

H. Cámara de Diputados de la Nación. Reunión 10ª - $7^{\mathrm{a}}$ Sesión Ordinaria (Especial). http://www.oas.org/es/cidh/multimedia/2015/violencia-lgbti/terminologia-lgbti.html. Laski, M. (1998). "Mujeres, vulnerabilidades y género". Incluido en el Cuaderno Mujer Salud $\mathrm{n}^{\circ}$ 3, de la Red de Salud de las Mujeres Latinoamericanas y del Caribe.

Mola, L. M.; Rodríguez Gil, S. G.; Rebagliati, P. J. (agosto 2005). “Cromosomas sexuales: Cien años y una historia”. En Encrucijadas, no. 34, Universidad de Buenos Aires. Disponible en http://repositoriouba.sisbi.uba.ar.

Salmo 8, 4/6.

Scola, A. (2003). La cuestión decisiva del amor: hombre-mujer. Madrid. Ed. Encuentro. 